\title{
DESENVOLVIMENTO DE HABILIDADES INFORMACIONAIS: UM ESTUDO DAS ATIVIDADES DE EDUCAÇÃO DE USUÁRIOS APLICADAS NA BIBLIOTECA DO COLÉGIO ISRAELITA ${ }^{1}$
}

\section{DESARROLLO DE HABILIDADES INFORMACIONALES: UN ESTUDIO DE LAS ACTIVIDADES DE FORMACIÓN DE USUARIOS IMPLEMENTADO EN LA BIBLIOTECA DEL COLEGIO ISRAELITA}

Regina Dioga Pelissaro - reginapel@ig.com.br Bacharel em Biblioteconomia pela Universidade Federal do Rio Grande do Sul (UFRS).

Ana Maria Mielniczuk de Moura - ana.mmoura@uol.com.br Doutora em Comunicação e Informação (PPGCOM/UFRGS). Professora do Departamento de Ciência da Informação da Universidade Federal do

Rio Grande do Sul (UFRS).

\section{RESUMO}

Introdução: Para atingir a competência informacional é preciso aprender habilidades de busca e uso da informação, que devem começar a ser desenvolvidas desde cedo através das atividades de educação de usuários aplicadas nas bibliotecas escolares. Avaliar as ações de educação de usuários é válido para constatar se as crianças internalizam os conhecimentos que lhes são repassados.

Objetivo: Analisar a relação das habilidades desenvolvidas pelas crianças de $1^{\circ}$ ano do Ensino Fundamental do Colégio Israelita de Porto Alegre/RS, com as habilidades propostas pela autora Kuhlthau para a fase I, $1^{\text {a }}$ etapa, correspondente à idade dos quatro aos seis anos.

\footnotetext{
${ }^{1}$ Síntese do trabalho de conclusão de curso apresentado ao Departamento de Ciência da Informação/UFRGS, como parte dos requisitos para obtenção do grau de bacharel em Biblioteconomia.
} 
Metodologia: Os dados foram coletados por observação e grupo focal e foram analisados qualitativamente.

Resultados: Os resultados indicam que as crianças possuem a maioria das habilidades propostas pela autora e aquelas que não estão completamente desenvolvidas podem ser melhoradas através das atividades propostas neste estudo e, outras, no final do ano, quando completarem a alfabetização.

Conclusões: $O$ estudo considera as avaliações essenciais, pois através delas se constata se os alunos adquiriram as habilidades praticadas nas ações de educação de usuários.

Palavras-chave: Desenvolvimento de habilidades informacionais. Educação de usuários. Biblioteca escolar. Avaliação de habilidades informacionais.

\section{INTRODUÇÃO}

Muito antes de se começar a articular a competência informacional já se conhecia a educação de usuários. Contudo, foi com o surgimento da primeira que a segunda ganhou mais espaço nas discussões bibliotecárias e, consequentemente, mais importância.

A competência informacional surgiu como consequência do fenômeno global sociedade da informação que é caracterizada pela grande quantidade de informação disponibilizada em diversos formatos tecnológicos, requerendo a aprendizagem de habilidades para lidar com esse novo ambiente informacional altamente complexo. No entanto, as habilidades exigidas para se chegar à competência informacional precisam ser obtidas durante um processo de aprendizagem, que em algum momento deve ser iniciado.

Acredita-se que a escola seja o melhor espaço para se começar a desenvolver as habilidades informacionais, por meio das atividades de educação de usuários, gerando nas crianças, desde cedo, competências de busca e uso da informação, para que elas passem a ser usuárias autônomas de qualquer biblioteca e serviço de informação. As atividades de educação de usuários são uma forma das crianças terem mais contato com a biblioteca tornando-se uma prática favorável a sua iniciação no meio informacional.

Para auxiliar o desenvolvimento das habilidades informacionais na escola, a bibliotecária Carol Kuhlthau, criou um programa de desenvolvimento gradual de habilidades de localização e interpretação em alunos de quatro a catorze anos. A proposta é encontrada no livro Como usar a biblioteca escolar: um programa de 
atividades para o ensino fundamental, adaptado por um grupo de pesquisadores da Escola de Ciência da Informação da Universidade Federal de Minas Gerais, e está dividida em fases e etapas, onde em cada uma são apresentadas atividades para desenvolver nas crianças as habilidades referentes à idade à qual elas se encontram. Na fase I, $1^{\underline{a}}$ etapa, fase utilizada neste estudo, Kuhlthau (2006, p. 27), propõe que "[...] as crianças irão aprender o que é uma biblioteca, capacitando-se a seguir rotinas e procedimentos. Vão se familiarizar com uma variedade de materiais e terão experiência de interação com os colegas." Assim, o programa, nesta fase, desenvolve as habilidades de usar a biblioteca e a informação, tendo como principal atividade a leitura de uma variedade de livros e histórias interessantes para as crianças.

Contudo, não basta apenas aplicar programas de educação de usuários, é importante avaliá-los para constatar se eles estão atingindo os objetivos de gerar as habilidades informacionais de acordo com a faixa etária das crianças. Através da avaliação o bibliotecário estará ciente de que seus usuários estão obtendo as habilidades informacionais que os tornarão competentes em informação, uma vez que as avaliações fornecem dados sobre o desempenho dos alunos e evidenciam a importância da biblioteca na aprendizagem (CAMPELLO, 2009), entendendo-se que a avaliação faz parte do programa de educação de usuários.

Diante de tais fatos, essa pesquisa buscou verificar nas crianças do $1^{\circ}$ ano do Ensino Fundamental do Colégio Israelita de Porto Alegre/RS como está o desenvolvimento das suas habilidades informacionais. Para avaliar o desenvolvimento das habilidades das crianças, utilizou-se a proposta de Kuhlthau (2006), analisando-se a relação entre as atividades de educação de usuários desenvolvidas pela Biblioteca do Colégio Israelita e as habilidades informacionais propostas pela autora.

O Colégio Israelita foi escolhido por estar entre os cinco melhores colégios particulares no Exame Nacional do Ensino Médio (ENEM) de 2009 e o $1^{\circ}$ ano, pelo fato de as crianças estarem na idade do primeiro contato com bibliotecas e onde começam a se relacionar com o mundo letrado.

Em pesquisas qualitativas envolvendo crianças, é necessário considerar o comportamento delas durante a coleta de dados. Kuhlthau (2006) diz ser difícil prender a atenção de uma classe de crianças pequenas, fazendo com que fiquem 
quietas e escutem o que os outros falam. Diz ainda, que as crianças possuem dificuldades em fixar sua atenção durante uma discussão em grupo, sentindo-se ansiosas para contribuir. Contudo quando falam costuma ser fora do assunto discutido no momento. Tais situações ocorreram durante a coleta dos dados da pesquisa, havendo crianças desatentas ou mesmo ansiosas para colaborar.

O Colégio Israelita Brasileiro iniciou suas atividades em junho de 1922. O Israelita valoriza a memória, habilita seus alunos a uma participação produtiva num mundo plural e enfatiza a qualidade das relações humanas na formação de seus jovens, visando transformar a Escola em referência de educação no Brasil. $O$ Colégio conta hoje com 753 alunos, desde a Educação Infantil até o $3^{\circ}$ ano do Ensino Médio. No ensino utilizam o português e o hebraico para que os alunos tenham contato com a língua do povo judeu. A Biblioteca Vira Letra-Vira Livro é o espaço infantil, usado pela Educação Infantil e séries iniciais, até o quarto ano. E a Biblioteca Pedro Birmman é utilizada pelos alunos do quinto ano ao Ensino Médio. ${ }^{2}$

A Biblioteca do colégio possui atividades de educação de usuários voltadas para todas as turmas de alunos, sendo elas: uso do computador; hora do conto; feira do livro; monitoria; visita guiada; e agendamento da Biblioteca. A variedade de atividades mostra que o colégio possui uma forte preocupação com a formação dos seus alunos, chamando sua atenção aos diversificados produtos e serviços oferecidos pela Biblioteca e ensinando-os a utilizá-los corretamente.

O estudo realizado é um relato de experiência cuja coleta de dados foi obtida por meio de grupo focal e observação sistemática. O grupo focal é tido como uma conversa entre os participantes e não apenas uma interação com o pesquisador (BARBOUR, 2009), ainda que para trabalhar com crianças tenha sido necessário realizar adaptações ao instrumento. Porém, isso não chega a ser uma desvantagem, uma vez que Mauthner (1997, p. 23 apud BARBOUR 2009, p. 128) afirma que: "Grupos focais são geralmente considerados mais apropriados que entrevistas individuais para crianças pequenas." Já a observação sistemática, segundo Gil (2010), é empregada quando já se tem conhecimento de quais são os aspectos significativos a serem observados. Isso ocorreu neste estudo, uma vez que se

\footnotetext{
${ }^{2}$ Informações retiradas do site da Instituição: http://www.colegioisraelita.com.br/

${ }^{3}$ MAUTHNER, M. Methodological aspects of collecting data from children: lessons from three research projects, Children and Society, 11, p. 16-28, 1997. Apud BARBOUR, Rosaline. Grupos Focais. Porto Alegre: Artmed, 2010. p. 127.
} 
estabeleceu que fossem examinadas as habilidades propostas pela autora Kuhlthau para a fase I, $1^{\underline{a}}$ etapa.

Os sujeitos do estudo são os alunos da turma "T11", do $1^{\circ}$ ano do Colégio Israelita que frequentam o colégio desde os quatro anos de idade. Tal recorte foi feito porque se acredita que participando da comunidade escolar há dois anos as crianças já estejam familiarizadas com a biblioteca e possuam contato com o programa de educação de usuários. As atividades de observação foram realizadas com dez crianças e o grupo focal foi realizado com seis crianças.

A coleta dos dados foi realizada em cinco visitas previamente agendadas. Nas atividades, as observações foram anotadas e o grupo focal foi filmado para analisar melhor as falas dos sujeitos e suas expressões. Antes da realização da coleta de dados, foi enviado aos pais um termo de consentimento, ao qual eles assinaram, autorizando os filhos a participarem da pesquisa. No termo foi esclarecido que todas as informações coletadas eram para fins de pesquisa e que seria mantido o anonimato das crianças.

Para melhor aproveitamento dos dados, todas as informações coletadas foram transcritas. Depois, os dados foram organizados em categorias de análise, de acordo com as habilidades definidas pela autora Kuhlthau (2006) para a fase I, $1^{\text {a }}$ etapa pesquisada. Posteriormente foi realizada a aplicação do método de análise de conteúdo para relacionar os dados obtidos com os aspectos estudados.

Em relação à descrição da análise dos dados, preferiu-se preservar a identidade dos sujeitos, optando-se por referir-se a eles usando números de 1 a 10 . De igual forma, manteve-se o anonimato das pessoas mencionadas pelos sujeitos.

Antes de se exporem os resultados aos quais o estudo se propôs, apresentase uma breve revisão de literatura. Nesta revisão procurou-se expressar o valor da biblioteca escolar, da competência informacional e da educação de usuários para o desenvolvimento exitoso das habilidades informacionais. E ao final, encontram-se as análises e os resultados da pesquisa apresentando o conceito de biblioteca criado pelos alunos; uma comparação entre as habilidades propostas por Carol C. Kuhlthau para crianças de quatro a seis anos com as habilidades adquiridas pelos sujeitos estudados; e a proposta de novas atividades de educação de usuários para serem desenvolvidas com os alunos. 


\section{A BIBLIOTECA ESCOLAR}

Segundo o Manifesto IFLA/UNESCO para bibliotecas escolares: "A biblioteca escolar habilita os estudantes para a aprendizagem ao longo da vida e desenvolve a imaginação, preparando-os para viver como cidadãos responsáveis" (IFLA; UNESCO, 2002, p. 1).

A biblioteca escolar, como dinamizadora da ação educacional precisa ter: acervo adequado às necessidades dos alunos; equipamento apropriado; pessoal capacitado e especializado; e entrosamento direção-professores-bibliotecário (SANTOS, 1989). O espaço físico deve ser iluminado, arejado, e aconchegante para atrair os usuários. O acervo não deve ser constituído majoritariamente de livros didáticos, devendo ter uma coleção diversificada, que facilite o apoio às atividades exigidas pelos professores nas matérias curriculares, além de formar usuários criativos, críticos e construtores de novos conhecimentos.

Em relação aos serviços oferecidos pela biblioteca escolar, Kieser e Fachin (2000) corroboram a utilização do imaginário das crianças para atraí-las à biblioteca.

E em hipótese alguma se podem esquecer os objetivos da biblioteca escolar:

a) apoiar e intensificar a consecução dos objetivos educacionais definidos na missão e no currículo da escola;

b) desenvolver e manter nas crianças o hábito e o prazer da leitura e da aprendizagem, bem como o uso dos recursos da biblioteca ao longo da vida;

c) oferecer oportunidades de vivências destinadas à produção e uso da informação voltada ao conhecimento, à compreensão, imaginação e ao entretenimento;

d) apoiar todos os estudantes na aprendizagem e prática de habilidades para avaliar e usar a informação, em suas variadas formas, suportes ou meios, incluindo a sensibilidade para utilizar adequadamente as formas de comunicação com a comunidade [...] onde estão inseridos;

h) proclamar o conceito de que a liberdade intelectual e o acesso à informação são pontos fundamentais à formação de cidadania responsável e ao exercício da democracia;

i) promover leitura, recursos e serviços da biblioteca escolar junto à comunidade escolar e ao seu derredor (IFLA/UNESCO, 2002, p. 2).

Os objetivos citados acima são alcançados mais facilmente com a ajuda do bibliotecário escolar, pois este apoia as atividades dos professores oferecendo 
recursos informacionais para que tais atividades sejam alcançadas. Também ensina os alunos a não realizarem os trabalhos de "copia e cola" tão prejudiciais ao seu desenvolvimento. "Assim, ao mesmo tempo, o bibliotecário ensina a socialização, através do compartilhamento de informações, de utilização de materiais e ambientes coletivos, preparando o aluno para o desenvolvimento social e cultural" (BONOTTO, 2007, p. 168-169), uma vez que a biblioteca escolar é um espaço para "[...] formação e informação, em que a aprendizagem de conteúdos deve necessariamente favorecer a inserção do aluno no dia-a-dia das questões sociais marcantes e em um universo cultural maior." (BRASIL, 1997, p. 33, grifo nosso). Por isso, a biblioteca escolar deve ser vista como uma forte parceira educativa à disposição dos estudantes e professores, sendo uma organização inovadora, criativa, dinâmica e convidativa. Ela é o principal apoio à sala de aula, favorecendo o desenvolvimento curricular e estimulando a criatividade e o conhecimento dos alunos, independente de sua faixa etária. Além disso, a biblioteca é o principal espaço para o desenvolvimento das habilidades informacionais por ser um local dotado de informação e um espaço de socialização do conhecimento, devendo promover o uso eficiente da informação e, consequentemente, oferecendo um processo educativo que leve o aluno a adquirir gradativamente a competência informacional.

\section{COMPETÊNCIA INFORMACIONAL}

A competência informacional, traduzida do termo Information Literacy, surgiu nos Estados Unidos. Atualmente ela caracteriza a sociedade da informação, um fenômeno global de transformações de atividades sociais e econômicas, requerendo das pessoas uma aprendizagem permanente. Dudziak (2003, p. 28) definiu-a como: "[...] o processo contínuo de internalização de fundamentos conceituais, atitudinais e de habilidades necessário à compreensão e interação permanente com o universo informacional e sua dinâmica, de modo a proporcionar um aprendizado ao longo da vida." Assim, a competência informacional demonstra uma preocupação em tornar as pessoas capazes de articular a informação durante toda a vida.

Campello (2006) defende que a competência informacional deve ser experimentada pelas crianças ainda no início da vida escolar, familiarizando o aluno 
desde cedo com o aparato informacional do mundo letrado. Tal afirmação é confirmada por Cavalcante (2006, p. 55-56) quando diz que "[...] o desenvolvimento adquirido durante os anos de escola, poderá funcionar como sólidas bases para a formação acadêmica e exercício futuro de uma determinada carreira, em todos os aspectos."

Se a biblioteca escolar possuir programas e atividades que desenvolvam nos alunos as competências informacionais, ela amplia seu processo educativo, uma vez que estará inserida no âmbito dos conteúdos curriculares. É na escola que o aluno deve conhecer as fontes de informação que pode usar, e aprender como tirar o maior proveito delas. É nesse espaço que ele precisa iniciar seu pensamento crítico; começar a formular questões; avaliar e utilizar a informação. Dessa forma, ele aprende a aprender e tudo o que ele conhece na escola se torna pretexto para tornar-se um indivíduo pró-ativo.

Para facilitar o desenvolvimento das habilidades informacionais na biblioteca escolar, o bibliotecário deve fazer uso das atividades de educação de usuários, que são um "[...] processo pelo qual o usuário interioriza comportamentos adequados com relação ao uso da biblioteca e [...] de interação permanente com o sistema de informação" (OLIVEIRA, 2000).

No projeto de educação de usuários podem estar inseridas atividades como: palestras, visitas guiadas, apresentações audiovisuais, distribuição de folhetos, interação com livros e filmes, entre outras. As atividades devem ser pensadas de acordo com a faixa etária dos alunos a fim de cultivar neles o desejo inato de saber. E conforme a vida escolar avança, a criança passa "[...] a reconhecer na biblioteca um elemento fundamental para o seu desenvolvimento intelectual" (CARVALHO, 1981, p. 25), desenvolvendo as habilidades de localização e interpretação delineadas por Kuhlthau (2006).

Para Kuhlthau (2006, p. 20): "As habilidades de localização ajudam os alunos a entender como os materiais são organizados, possibilitando-lhes localizarem uma informação ou um material específico." Em relação às habilidades de interpretação, Kuhlthau (2006) assegura que elas ajudam os alunos a entender e usar os materiais da biblioteca de forma que possam escolher os recursos adequados para informação e entretenimento, permitindo que eles tomem conhecimento de informações 
acessíveis, dominem habilidades para localizar os materiais desejados e tenham competência para avaliá-los, selecioná-los e interpretá-los.

Para saber se os alunos do Colégio Israelita possuíam as habilidades de localização e interpretação propostas por Kuhlthau (2006) para a fase $1,1^{\text {a }}$ etapa, foi analisado, nas crianças, o comportamento diante do aparato informacional oferecido pela biblioteca e o conhecimento sobre a biblioteca e seu materiais, iniciando-se por conhecer qual é a ideia que eles têm da biblioteca.

\section{$4 \quad$ RESULTADOS}

\subsection{O Conceito de Biblioteca}

Faz-se sempre importante reconhecer o que as crianças entendem por biblioteca, pois isso mostra quanto integradas com a Biblioteca elas se encontram.

De acordo com Vygotsky (1998) o desenvolvimento dos conceitos pressupõe o desenvolvimento de muitas funções intelectuais, dentre elas a atenção deliberada, memória lógica, abstração, capacidade para comparar e diferenciar. Para Targino (1983) a aprendizagem tende a aperfeiçoar-se ao longo do processo, dependendo das oportunidades oferecidas ao indivíduo e que por meio de tais oportunidades, ele vai estabelecer o conceito. Então, no caso da biblioteca escolar, o aluno vai formar o seu conceito de biblioteca de acordo com o contato que ele possui com este espaço e seus produtos e serviços no decorrer de sua vida escolar. Sendo assim, perguntou-se aos sujeitos o que era biblioteca para eles e suas concepções foram as seguintes:

\footnotetext{
"A biblioteca é um lugar que a gente pode ler e que as pessoas não podem fazer barulho senão elas nos atrapalham" (Sujeito 8).

"É um lugar que a gente tira livros pra ler na biblioteca ou em casa e tem que fazer silêncio pra ler o livro" (Sujeito 3).

"Lugar onde a gente pode ler ou retirar livro, mas depois tem que devolver de novo" (Sujeito 2).
}

De modo geral, os sujeitos comprovaram saber o que é a biblioteca, pois seus conceitos estão de acordo com o que eles vivenciam quando estão neste espaço, uma vez que citaram as principais atividades que realizam ali, sendo elas, retiradas de livros, leitura e contação de histórias. 
A conceituação é importante porque, segundo Targino (1983), o conceito de biblioteca tem influência das variáveis do ambiente escolar e por meio destas a criança passa a ter reações que the possibilitam identificar biblioteca e mostrar que a aprendizagem foi realizada. No Colégio Israelita as crianças recebem a sequência de estímulos de contato com a biblioteca e mencionados pela autora, desde quando manipulam os livros e realizam o empréstimo, por exemplo, passando a ter as reações e podendo distinguir o que é biblioteca.

Após verificar o conceito de biblioteca das crianças e, por isso, já tendo uma ideia do que elas sabem sobre a biblioteca, seus materiais e serviços, é apresentada a comparação entre as habilidades desenvolvidas pelos alunos do Colégio Israelita e as habilidades de localização e interpretação propostas por Carol Kuhlthau. Segundo Campello (2009) muitas escolas têm utilizado as habilidades informacionais para compor estruturas que auxiliam na implementação de programas de educação de usuários planejando ações que tenham um propósito e possam ser atingidas pelos alunos das diferentes idades que frequentam o colégio. A comparação apresentada a seguir mostrar se há relação entre as atividades de educação de usuários da Biblioteca do Colégio Israelita e as habilidades propostas por Carol Kuhlthau.

\subsection{Habilidades Desenvolvidas Pelos Alunos Versus Habilidades Propostas por Kuhlthau}

Para verificar se as ações aplicadas na Biblioteca do Colégio Israelita geram nas crianças as habilidades propostas para a faixa etária, atribuindo-Ihes autonomia no aprender a aprender, relacionou-se as habilidades desenvolvidas pelos sujeitos e as habilidades propostas por Kuhlthau (2006) para a fase I, 1ㄹ etapa. A relação das habilidades é apresentada nos Quadros 1 e 2 com as análises dos sujeitos e abaixo um comentário relacionando as habilidades proposta pela autora com as habilidades desenvolvidas pelos sujeitos. 


\subsubsection{Habilidades de localização}

As habilidades de localização, nesta etapa, referem-se ao reconhecimento do arranjo da coleção, ajudando os alunos a entender como os materiais são organizados, possibilitando-Ihes localizarem um material específico e permitindoIhes, mais tarde, entender um ambiente informacional (KUHLTHAU, 2006).

De acordo com Kuhlthau (2006) e Campello (2009) é importante que as crianças conheçam o arranjo da coleção da biblioteca para ir adquirindo autonomia e encontrarem os livros que buscam. Destacam que, além disso, as crianças alcançam segurança e estímulo para utilizarem sozinhas outras bibliotecas que venham a necessitar no futuro. As habilidades de localização são apresentadas no Quadro 1 (abaixo).

Quadro 1 - Habilidades de localização

\begin{tabular}{|c|c|}
\hline $\begin{array}{c}\text { HABILIDADE/ } \\
\text { TÉCNICA UTILIZADA }\end{array}$ & OBSERVAÇÕES DOS SUJEITOS \\
\hline $\begin{array}{l}\text { Habilidade 1: sabe que os } \\
\text { materiais da biblioteca estão } \\
\text { organizados numa determinada } \\
\text { ordem } \\
\text { Grupo focal. Perguntas: como } \\
\text { você encontra o livro que quer } \\
\text { ler? Onde você deixa o livro } \\
\text { depois que leu? Por quê? }\end{array}$ & $\begin{array}{l}\text { "[...] às vezes a S. ainda não bota nas prateleiras [...]", pois títulos } \\
\text { novos, às vezes, não são colocados na estante, ficando um } \\
\text { tempo no balcão de empréstimo, como novidade. } \\
\text { Quando indagados se guardam o livro de volta na estante, o } \\
\text { sujeito } 1 \text { disse: "Se a gente puxou e não era aquele, daí a S. não } \\
\text { deixa a gente colocar no lugar de volta. Ela pede pra gente } \\
\text { colocar naquele lugar do lado da prateleira." (Sujeito 1). O sujeito } \\
4 \text { complementou dizendo que fazem isso, porque "[...] cada livro } \\
\text { tem seu lugar." }\end{array}$ \\
\hline $\begin{array}{l}\text { Habilidade } 2 \text { está } \\
\text { desenvolvendo a compreensão } \\
\text { de sua responsabilidade na } \\
\text { manutenção da ordem dos } \\
\text { materiais } \\
\text { Observação na Biblioteca. }\end{array}$ & $\begin{array}{l}\text { Na observação feita, a maioria dos sujeitos não escolheu seu } \\
\text { livro na estante, pois preferiu ficar com os livros da coleção } \\
\text { "Quem tem medo", entregues pela professora. Assim, dentre os } \\
\text { sujeitos que foram às estantes, observou-se que o sujeito } 3 \\
\text { puxava o livro até conseguir ler o título e empurrava-o de volta, } \\
\text { sem tirá-lo totalmente do seu lugar. E o sujeito } 9 \text { afastou o } \\
\text { bibliocanto abrindo espaço entre os livros e passou-os de um } \\
\text { lado para outro, deixando-os todos na mesma ordem. }\end{array}$ \\
\hline
\end{tabular}

Fonte: elaborado pela autora, 2012.

$\mathrm{Na}$ habilidade 1, as crianças disseram que quando buscam um título específico dirigem-se a auxiliar S. e perguntam se a Biblioteca possui o título e se está disponível. Os sujeitos também afirmaram que não guardam os livros de volta na estante, e justificaram dizendo que se colocarem de volta e o lugar estiver errado, algum colega pode procurar o livro e não encontrar. Então, verificou-se que os alunos estão cientes de que os livros possuem seu "endereço" na estante e que é possível encontrá-los, bem como existe alguém que sabe ensinar onde encontrá-los. 
Também comprovaram saber que não podem colocar o livro em qualquer lugar na estante, pois alguém pode precisar do livro, procurá-lo e não encontrá-lo.

A habilidade 2 tem por finalidade constatar a forma como os alunos agem no ambiente da biblioteca e como se comportam utilizando os materiais disponíveis para seu acesso. Está relacionada à habilidade anterior, uma vez que, reconhecendo a existência de uma ordenação do acervo, os alunos são aconselhados a mantê-la. Assim, o aluno tem o direito de usar os materiais e a responsabilidade de conservá-los em sua ordem. (KUHLTHAU, 2006).

A atitude dos sujeitos, conforme mostra o Quadro 1, demonstra que eles compreendem a sua responsabilidade na organização da biblioteca e procuram manter a ordem dos materiais enquanto elegem o livro que irão levar para casa por empréstimo, desenvolvendo a atitude de respeito mútuo comentada por Kuhlthau (2006).

\subsubsection{Habilidades de interpretação}

As habilidades de interpretação, nesta fase, são mais básicas e estão relacionadas às técnicas de avaliação e seleção de livros para leitura e empréstimo; a iniciação do aluno na interpretação dos materiais, começando pela hora do conto, onde ele procura os significados na história e compartilha as ideias sobre esse significado; e a apreciação literária, onde ele elege suas histórias e personagens favoritos (KUHLTHAU, 2006). Tais habilidades são apresentadas no Quadro 2 (abaixo). 
Quadro 2 - Habilidades de interpretação

\begin{tabular}{|c|c|}
\hline $\begin{array}{c}\text { HABILIDADE/ } \\
\text { TÉCNICA UTILIZADA }\end{array}$ & OBSERVAÇÕES DOS SUJEITOS \\
\hline $\begin{array}{l}\text { Habilidade 1: sabe que a biblioteca } \\
\text { tem livros para emprestar e usar } \\
\text { Grupo focal. Pergunta: o que você } \\
\text { faz quando vai à Biblioteca? }\end{array}$ & $\begin{array}{l}\text { No geral, os sujeitos disseram que retiram e leem livros, e } \\
\text { ouvem histórias. } \\
\text { "Gosto de retirar livros e pode ler um pouco antes de retirar" } \\
\text { (Sujeito 2). O sujeito } 1 \text { comentou que "[...] pode, assim, ler } \\
\text { uma pagininha antes de pegar e ir lá na S. [pra retirar o livro]. } \\
\text { Daí a gente vê se [o livro] é legal ou não." }\end{array}$ \\
\hline $\begin{array}{l}\text { Habilidade 2: sabe que muitas } \\
\text { crianças usam a biblioteca }\end{array}$ & $\begin{array}{l}\text { "Todas as crianças do colégio e qualquer pessoa pode ir lá } \\
\text { usar. [...]" (Sujeito 1). A aluna quis dizer que não são apenas }\end{array}$ \\
\hline $\begin{array}{l}\text { Grupo focal. Pergunta: além de } \\
\text { você e seus colegas, quem mais } \\
\text { pode usar a Biblioteca? }\end{array}$ & $\begin{array}{l}\text { "alunos" que podem frequentar a Biblioteca, outras pessoas } \\
\text { também podem, mas desde que façam parte da comunidade } \\
\text { judaica. Os outros sujeitos disseram que todas as turmas do } \\
\text { colégio podem usar a Biblioteca. }\end{array}$ \\
\hline $\begin{array}{l}\text { Habilidade 3: consegue, com a } \\
\text { ajuda do bibliotecário, escolher um } \\
\text { livro para levar para casa por } \\
\text { empréstimo }\end{array}$ & $\begin{array}{l}\text { Na Biblioteca, os alunos têm a liberdade de buscar os livros na } \\
\text { estante sozinhos e/ou trocando opiniões com os colegas. } \\
\text { Conforme vão passando de ano podem buscar em estantes de } \\
\text { cores diferentes. }\end{array}$ \\
\hline & $\begin{array}{l}\text { Quanto à eleição dos livros para empréstimo, atualmente, os } \\
\text { sujeitos costumam retirar os livros da coleção "Quem tem } \\
\text { medo" fazendo um rodízio entre eles, como já foi comentado } \\
\text { nas habilidades de localização. }\end{array}$ \\
\hline $\begin{array}{l}\text { Habilidade 4: consegue cuidar dos } \\
\text { livros que levou por empréstimo ou } \\
\text { que usa na biblioteca }\end{array}$ & $\begin{array}{l}\text { A gente pega e abre com cuidado. (Sujeito } 8 \text { ). } \\
\text { Eu pego o livro e, daí tento não rasgar quando eu abro. Cuido } \\
\text { bem dos livros. (Sujeito } 4 \text { ). }\end{array}$ \\
\hline $\begin{array}{l}\text { Grupo focal. Perguntas: como você } \\
\text { trata os livros da Biblioteca? Que } \\
\text { cuidados você tem com os livros } \\
\text { da Biblioteca? }\end{array}$ & $\begin{array}{l}\text { [...] se eu não tivesse percebido que estava rasgado, eu ia } \\
\text { chegar em casa, eu ia colar o livro, se tivesse rasgado. Daí, se } \\
\text { eu tivesse tomando água e derramar água eu ia tentar } \\
\text { comprar outro. Só que aí a gente cuida pra não acontecer } \\
\text { isso. (Sujeito } 1 \text {, sic). }\end{array}$ \\
\hline $\begin{array}{l}\text { Habilidade 5: dá conta de seguir as } \\
\text { rotinas de empréstimo } \\
\text { Observação na Biblioteca e grupo } \\
\text { focal. Perguntas: você devolve o } \\
\text { livro na data de devolução? Você } \\
\text { assina a ficha de empréstimo? }\end{array}$ & $\begin{array}{l}\text { Os sujeitos disseram que devolvem os livros na data certa ou } \\
\text { mesmo antes de vencer o prazo. } \\
\text { A segunda pergunta gerou uma discussão entre os sujeitos, } \\
\text { pois o empréstimo é informatizado e os alunos não assinam } \\
\text { "ficha de empréstimo". Então, o sujeito } 3 \text { explicou como é } \\
\text { realizado o empréstimo: "A S., ela tem uma carteirinha, que } \\
\text { ela pega uma máquina que ela passa nos livros e aí imprime } \\
\text { um papelzinho (comprovante com a data de devolução do } \\
\text { livro) que ela põe dentro dos livros." }\end{array}$ \\
\hline $\begin{array}{l}\text { Habilidades } 6 \text { e } 7: \text { está } \\
\text { desenvolvendo habilidades de } \\
\text { observar as imagens e sons da } \\
\text { história e está desenvolvendo } \\
\text { habilidades de reagir ao que é } \\
\text { visto e ouvido } \\
\text { Observação na sala de aula e na } \\
\text { Biblioteca. }\end{array}$ & $\begin{array}{l}\text { Na contação observada na sala de aula, os alunos estavam } \\
\text { sentados em suas mesas, em grupos de quatro. Vários alunos } \\
\text { interromperam a contação para ir ao banheiro ou caminhando } \\
\text { pela sala. Apenas três sujeitos prestaram atenção em toda a } \\
\text { história, outros estavam dispersos ou ausentes da sala de aula } \\
\text { durante toda a contação. Os comentários sobre a história } \\
\text { foram feitos após seu término, quando a professora, com } \\
\text { perguntas, estimulou os alunos a falarem. } \\
\text { A segunda contação foi na Biblioteca Vira Letra-Vira Livro. Os } \\
\text { alunos sentaram-se em almofadas formando um círculo no } \\
\text { chão da Biblioteca. Nesta ocasião nenhum aluno pediu para } \\
\text { sair da Biblioteca durante a leitura da história e apenas o } \\
\text { sujeito } 4 \text { aparentou estar disperso. Desta vez, os alunos } \\
\text { fizeram seus comentários durante a contação, sem a } \\
\text { necessidade de serem estimulados pela professora. }\end{array}$ \\
\hline $\begin{array}{l}\text { Habilidade 8: está desenvolvendo } \\
\text { habilidades de usar links e } \\
\text { identificar ícones em documentos }\end{array}$ & $\begin{array}{l}\text { As duplas digitaram login e senha nos computadores e } \\
\text { algumas, sentindo dificuldades, pediram ajuda para inserir as } \\
\text { informações e para escrever a senha, uma vez que ainda não }\end{array}$ \\
\hline
\end{tabular}



usuários aplicadas na biblioteca do Colégio Israelita

\begin{tabular}{|c|c|}
\hline $\begin{array}{l}\text { hipertextuais } \\
\text { Observação no Laboratório de } \\
\text { Informática }\end{array}$ & $\begin{array}{l}\text { estão alfabetizados. } \\
\text { No jogo de palavra cruzada, a maioria dos sujeitos entendeu } \\
\text { que devia clicar no número para a atividade avançar. Ainda } \\
\text { assim, alguns sujeitos precisaram de ajuda. E o sujeito } 7 \text { ainda } \\
\text { teve dificuldade para manusear o mouse. Quanto à escrita dos } \\
\text { nomes, grande parte das duplas mostravam-se inseguras em } \\
\text { escrever as palavras ou tinham dificuldade em reconhecer as } \\
\text { letras que formavam certas sílabas. } \\
\text { Na atividade de desenho, os sujeitos pintaram, desenharam, } \\
\text { carimbaram e escreveram, usando os recursos do programa, } \\
\text { demonstrando reconhecer os ícones disponíveis. }\end{array}$ \\
\hline $\begin{array}{l}\text { Habilidade 9: sabe que existem } \\
\text { muitos livros de história e de } \\
\text { imagens na biblioteca } \\
\text { Grupo focal. Pergunta: quais tipos } \\
\text { de livros você já viu na Biblioteca? }\end{array}$ & $\begin{array}{l}\text { Os livros mais citados pelos alunos foram de história, como a } \\
\text { coleção "Quem tem medo". Também houve as seguintes } \\
\text { citações: } \\
\text { "[...]Um dia eu li um livro de piadas [...]." (Sujeito 1). } \\
\text { Os livros de inventar "[...] esses que só tem o nome na capa." } \\
\text { (Sujeito } 1 \text { e Sujeito } 8 \text { ). }\end{array}$ \\
\hline $\begin{array}{l}\text { Habilidade 10: tem alguns livros e } \\
\text { personagens preferidos } \\
\text { Grupo focal. Perguntas: de todas } \\
\text { as histórias que você ouviu serem } \\
\text { contadas pela professora ou das } \\
\text { que você levou para ler em casa, } \\
\text { qual é a que você mais gosta? De } \\
\text { todas as histórias que você } \\
\text { conhece qual seu personagem } \\
\text { preferido? Por quê? }\end{array}$ & $\begin{array}{l}\text { Os livros preferidos dos sujeitos são os livros da coleção } \\
\text { "Quem tem medo". } \\
\text { Enquanto que os personagens preferidos, são personagens de } \\
\text { seriados de televisão e filmes, como a Carly, do seriado I } \\
\text { Carly, e Miley Stewart, a Hannah Montana e ainda os } \\
\text { personagens do Star Wars. Também foram citados os } \\
\text { personagens da coleção "Quem tem medo". }\end{array}$ \\
\hline $\begin{array}{lrr}\text { Habilidade 11: começa } & \text { a } \\
\text { desenvolver a capacidade } & \text { de } \\
\text { apreciar as peculiaridades } & \text { de } \\
\text { diversos tipos de poemas } & \end{array}$ & $\begin{array}{l}\text { Os alunos fizeram uma leitura da poesia junto com a } \\
\text { professora. Depois conversaram sobre o que era rima citando } \\
\text { algumas rimas conhecidas, como "oi cara de boi" e } \\
\text { comentaram rimas do próprio texto. Em seguida, criaram rimas } \\
\text { com seus próprios nomes, sem apresentar dificuldades na } \\
\text { realização da atividade. } \\
\text { O sujeito 5, entendendo a importância de se trabalhar poesia } \\
\text { sugeriu que eles lessem poesias nas outras turmas do colégio } \\
\text { para levar essas características literárias aos outros alunos. }\end{array}$ \\
\hline
\end{tabular}

Fonte: elaborado pela autora, 2012.

$\mathrm{Na}$ habilidade 1 - se a biblioteca tem livros pra emprestar e usar, os comentários feitos pelos alunos demonstram que eles reconhecem a principal função da biblioteca. Estes comentários, somados às observações da visita semanal agendada confirmaram que os alunos usam os livros na Biblioteca e também fazem empréstimos, uma vez que todos leram no espaço da Biblioteca e saíram dela com seu livro para ler em casa.

A habilidade 2 - muitas crianças usam a biblioteca, possui como finalidade constatar se os alunos reconhecem que outras pessoas usam a Biblioteca e que ela atende às variadas idades e turmas. Assim, as respostas dos sujeitos foram bastante apropriadas no sentido de responder à habilidade analisada, uma vez que todos provaram saber que sua turma não é a única a frequentar a Biblioteca. 
A habilidade 3 - escolher um livro para levar para casa por empréstimo, verifica se 0 aluno sabe escolher um livro que contenha uma história prazerosa e que o estimule a voltar à biblioteca e escolher outras narrações. Delacours-Lins (2008) afirma que as crianças buscam livros aos quais se identificam com as histórias, como é o caso da coleção "Quem tem medo", que trata de forma leve os temores das crianças. Assim, as observações realizadas, mostram que os sujeitos sabem escolher os livros que querem levar emprestados, pois parecem estar entusiasmados com as histórias escolhidas e na maioria das vezes comentam animadamente com os colegas o que leram, chegando até a indicá-las.

$\mathrm{Na}$ habilidade 4 - se a criança consegue cuidar dos livros, verifica-se o zelo dos alunos em relação à Biblioteca, seus materiais e equipamentos. Para Kuhlthau (2006), as crianças precisam entender que a biblioteca é um lugar público, um patrimônio coletivo e que zelar por ela é dever de todos. Portanto, as falas dos sujeitos mostram que eles são cientes de que não é possível ler um livro danificado e que, por isso, é preciso ter cuidado ao manuseá-lo. E caso se encontre algum livro avariado, o melhor é procurar arrumá-lo ao invés de simplesmente ignorá-lo. Contudo, suas ações na Biblioteca mostram que os sujeitos não tomam todos os cuidados com os livros, no sentido de apoiá-los e segurá-los. Mesmo assim infere-se que os sujeitos são bastante conscientes do cuidado que se deve ter com os materiais que são de todos.

A habilidade 5 - se a criança consegue seguir as rotinas de empréstimo, verifica se os alunos assimilaram a prática de rotina de empréstimo da Biblioteca. Os sujeitos disseram que devolvem o livro na data de devolução e também explicaram de forma correta como é realizado o empréstimo, o que foi constatado na observação. Também se observou que os alunos seguem as rotinas devolvendo e retirando seus livros no balcão de empréstimos, mostrando-se responsáveis pelo material que estão levando por empréstimo.

As habilidades 6 e 7 - se as crianças observam as imagens e sons da história e reagem ao que é visto e ouvido, foram analisadas conjuntamente, pois ambas estão relacionadas à hora do conto. Tais habilidades ponderam o nível de compreensão dos alunos em relação às histórias que ouvem diariamente na escola. Conforme Kuhlthau (2006, p. 32): "Compreender é encontrar significados no que está sendo lido." É interpretar o texto a partir do que está escrito e do conhecimento 
que a criança traz para o texto. A mesma autora diz que o momento certo para estimular as crianças a desenvolverem as habilidades de recordar, sumarizar, parafrasear e dar continuidade, competências básicas do uso de informação é dos quatro aos seis anos. Esse exercício abre espaço para as crianças reagirem e comentarem o que veem e ouvem, pois através destes recursos as crianças constroem os conhecimentos que necessitam para desenvolver sua personalidade (SOUZA, [2009], online).

Obteve-se, então, como resultado para as habilidades 6 e 7, que quando sentados no tapete no chão da Biblioteca as crianças se envolveram mais com a história contada. Isto pode ser atribuído ao fato de ter sido realizada em local apropriado, e não na sala de aula, local onde se realiza diversas outras atividades, propiciando a dispersão. Ainda assim entende-se que as crianças possuem as habilidades de ver, ouvir e interagir com as histórias, desde que estejam concentradas para isso, pois mostraram estar atentas ao que lhes era contado, fazendo comentários pertinentes ao enredo da história.

A habilidade 8 - se desenvolve as habilidades de usar links e identificar ícones em documentos hipertextuais, enfoca as noções de informática do aluno. Segundo Santos e Barros (2008), a tecnologia é considerada um elemento potencializador do desenvolvimento das capacidades humanas e pode ser trabalhada a partir dos primeiros anos de escola para promover o desenvolvimento da inteligência das crianças. $O$ que se observou nas atividades realizadas foi que a maioria dos alunos não possui domínio no uso do computador e precisa de ajuda desde o momento de acessar a máquina. Contudo, na atividade de desenho, onde eram livres para criar, os alunos não apresentaram problemas, utilizando, inclusive recursos que não estavam disponíveis na tela inicial, como a troca de tons das cores. Uma pequena comparação entre as duas brincadeiras realizadas evidencia que não saber realizar parte de uma atividade pode tê-los deixado apreensivos, bloqueando o seu raciocínio. Por isso, se propõe, nessa idade, jogos mais lúdicos, que estejam de acordo com o desenvolvimento do aluno.

A habilidade 9 - se a criança sabe que existem muitos livros de história e de imagens na biblioteca, é uma capacidade que está relacionada à apreciação literária. Através dela, é possível entender quais são os tipos de livros que os alunos conhecem. Sejam livros de história, imagéticos, de quadrinhos, entre outros. Apesar 
de os livros imagéticos, livros de pop-ups e histórias em quadrinhos não terem sido lembrados pelos alunos num primeiro momento, a Biblioteca possui tais acervos. Contudo, são materiais que os alunos não podem levar para casa, por isso não interagem com tanta frequência. Mas, é importante que a biblioteca deixe à disposição das crianças esses materiais pra que elas possam se conscientizar da variedade de livros disponíveis e desenvolverem o interesse por todos eles (KUHLTHAU, 2006).

A habilidade 10 - se a criança têm livros e personagens preferidos, está relacionada à preferência literária dos alunos, seus gostos por determinadas histórias e personagens. Através de suas respostas, os sujeitos mostram que possuem suas preferências em relação a histórias e personagens. E que elas estão de acordo com sua faixa etária, pois conforme Coelho (2000), autora que criou categorias de leitores, os alunos do $1^{\circ}$ ano são aqueles com gostos por histórias engraçadas, que estimulem a imaginação, as emoções, o sentir, ou que mesclem a fantasia e o real.

$\mathrm{Na}$ habilidade 11 - se a criança consegue apreciar as peculiaridades dos diversos tipos de poemas, verifica-se se o aluno começa a perceber a sonoridade das palavras e as questões culturais envolvidas com a poesia. Coelho (2000) diz que, paralelamente ao conhecimento objetivo e lógico de herança cultural, as crianças devem ser estimuladas a desenvolver seu potencial intuitivo e criativo. E o convívio com a poesia é uma das portas de entrada para o desenvolvimento dessas potencialidades e do desenvolvimento da consciência crítica. Então, as observações mostram que os sujeitos apreciam e entendem as peculiaridades dos poemas e a diferença de poesia e narração, através das suas próprias criações depois de trabalhar a poesia.

Analisando as habilidades de interpretação apresentadas, infere-se que os sujeitos possuem um desenvolvimento positivo das habilidades, uma vez que desenvolveram e estão desenvolvendo a maioria das habilidades propostas para a etapa aqui estudada. Esse resultado era esperado, uma vez que os sujeitos encontram-se no final da idade correspondente à etapa, estando praticamente competentes nas habilidades desta etapa e prontos para desenvolver novas habilidades informacionais. Entretanto, há habilidades às quais as crianças ainda apresentam pequenas dúvidas e inseguranças e as atividades propostas a seguir 
servem para ajudá-las a desenvolver plenamente tais habilidades bem como praticar mais as habilidades já desenvolvidas.

\subsection{Atividades Propostas à Biblioteca do Colégio Israelita}

Com base nas análises realizadas e no desempenho dos alunos no desenvolvimento das habilidades informacionais para a fase I, $1^{\text {a }}$ etapa, busca-se propor algumas novas atividades de educação de usuários para melhorar ainda mais a competência dos pequenos usuários da Biblioteca Vira Letra-Vira Livro. As sugestões procuram servir como mais um estímulo ao uso da Biblioteca e especialmente buscam contemplar as habilidades às quais as crianças ainda não desenvolveram integralmente, uma vez que se concorda com Carpallo Bautista ([2006]), quando diz que a formação de usuários deve ser entendida como um conjunto de atividades de caráter pedagógico, com o intuito de proporcionar a máxima utilização das possibilidades informativas da biblioteca.

Monfasani e Curzel (2006) dizem que as atividades propostas devem incluir um conjunto de dados, informações, conceitos e procedimentos que os usuários adquirirão durante o seu desenvolvimento. As mesmas autoras afirmam que é importante definir o "porque" e o "para que" de cada atividade. Assim, as atividades aqui recomendadas são sugestões dos próprios sujeitos, resultado da conversa no grupo focal, além das análises dos dados que apontaram serem necessárias algumas modificações no ensino para que a aprendizagem das habilidades seja concluída. As sugestões são ações diversificadas, para persuadir e encantar as crianças.

A primeira atividade, "Ensinando o cuidado com os livros" visa enfatizar o zelo pelos livros da Biblioteca. Para Kuhlthau (2006) a habilidade de zelar pelos livros é importante para ensinar às crianças desde cedo o valor de se cuidar do que é coletivo. A atividade surgiu depois das observações feitas durante a visita agendada à Biblioteca, onde se observou que as crianças não tinham todo o cuidado no manuseio dos livros, apesar de terem mostrado no grupo focal que estão cientes do zelo que se deve ter por eles. Propõe-se que esta atividade seja feita com as crianças de quatro a seis anos para que elas possam ir entendendo a importância do cuidado com os livros. 
A atividade consiste em mostrar às crianças vídeos sobre a importância de cuidar dos livros e expor algumas formas de cuidado. Depois de assistir aos vídeos, pede-se que cada uma das crianças desenhe um dos cuidados que se deve ter com o livro. Após, faz-se comentários sobre o desenho de cada um e ao final, se expõe os desenhos dos alunos na Biblioteca, nos corredores da escola e na sala de aula, como forma de promover o zelo com os materiais da Biblioteca. Sugere-se realizar a atividade sempre no início do ano letivo para que as crianças aprendam e/ou relembrem quais são os cuidados que se deve ter para não danificar os livros.

A atividade "Conhecendo o acervo de livros infantis" surgiu do desconhecimento dos sujeitos de alguns tipos de livros importantes para seu desenvolvimento, verificado na habilidade que tratava dos livros de história e de imagem na biblioteca. Então, se propõe que a Biblioteca realize uma atividade apresentando às crianças todos os tipos de livros que estão à sua disposição, desde as narrativas, até as histórias em quadrinhos.

Sugere-se que sejam distribuídos entre os alunos livros de história, de imagem, de poesia, de pop-ups e histórias em quadrinhos, ao menos dois exemplares de cada para que os alunos manuseiem esses matérias e possam se familiarizar com as variedades de livros existentes na Biblioteca, além de ensiná-los quais são as diferenças entre um livro e outro. Assim, a criança elege o livro que mais gosta, servindo como uma forma de incentivo à leitura. Outra finalidade é que as crianças interajam com os livros que não podem levar para casa por empréstimo, como os livros de pop-ups e as histórias em quadrinhos. A atividade pode ser feita no início do ano letivo para que as crianças aprendam e/ou relembrem o acervo.

"Navegando na história" é uma proposta de reformulação da atividade realizada no Núcleo de Informática, onde se sugere usar jogos e histórias simples e lúdicas que ajudem as crianças a desenvolverem a habilidade de interagir com documentos textuais. A preocupação é que a criança entenda o significado dos ícones e pratique o uso dos links e a movimentação do mouse. Autores como Santos e Barros (2008), Pacheco (2006) e Kuhlthau (2006) defendem o uso do computador na escola para que as crianças possam manipulá-lo e pouco a pouco prepararem-se para encarar os desafios impostos por estas tecnologias e chegarem sozinhos a soluções. Então, sugeriu-se para esta atividade um site bem simples e que está disponível na internet gratuitamente, cujo endereço é: "www.angela-lago.com.br". 
Esta atividade é indicada para as crianças do $1^{\circ}$ ano, mas pode ser usada em outros níveis também, trocando o material que é usado, podendo, por exemplo, usar histórias mais complexas. $\mathrm{Na}$ atividade a criança brinca com histórias, músicas infantis e até mesmo com as letras, e o mais importante, interagindo com os roteiros. Dessa forma, a criança começa a compreender o uso do computador e suas ferramentas e passa a usá-lo sem medos.

\section{CONSIDERAÇÕES FINAIS}

O estudo buscou verificar nas crianças do $1^{\circ}$ ano do Colégio Israelita, se elas possuíam as habilidades informacionais propostas por Kuhlthau (2006) para a fase I, $1^{\underline{a}}$ etapa. Para tanto, começou-se verificando qual era o conceito de biblioteca por parte dos sujeitos, assim se poderia mensurar sua proximidade com o espaço. As respostas das crianças mostraram que elas entendem, à sua maneira, o que é a biblioteca. Suas respostas eram curtas, porém descreviam tudo o que na sua idade praticam no ambiente, criando seu conceito de biblioteca.

A relação entre as habilidades propostas por Carol Kuhlthau e as habilidades dos sujeitos, apresentou um resultado de desenvolvimento completamente positivo para as habilidades de localização. Os sujeitos reconhecem que os materiais da Biblioteca possuem uma ordem relativa na estante e que é de sua responsabilidade ajudar a mantê-la, para que os outros usuários também encontrem o que procuram.

Já nas habilidades de interpretação, os resultados foram diferentes. Apesar de as crianças terem alcançado a maioria das habilidades, ainda há habilidades que necessitam melhor atenção por parte do colégio, que precisa pensar em preparar o espaço da contação de história na sala de aula, criando um ambiente acolhedor, ao invés de as crianças ouvirem as histórias sentadas em suas mesas de aula; e lembrar que os alunos estão em processo de alfabetização, tendo, portanto, que criar atividades mais lúdicas para o desenvolvimento de habilidades como a habilidade de uso de links e ícones em documentos hipertextuais.

Através das considerações feitas, conclui-se que, no geral, os alunos estão bem preparados para seguirem à próxima etapa de desenvolvimento de habilidades, uma vez que esta pesquisa foi realizada no início do ano letivo e as crianças possuem todo um ano pela frente para desenvolverem plenamente as habilidades às 
quais não dominam completamente. As atividades propostas neste estudo podem ser utilizadas pela Biblioteca para melhorar o desenvolvimento de tais habilidades.

Ainda, ressalta-se que não basta aplicar atividades às crianças no espaço da biblioteca, mas sim, faz-se importante avaliá-las. A avaliação faz parte do programa de educação de usuários, portanto deve ser utilizada para reconhecer se as crianças se identificam com as atividades de educação de usuários que thes são proporcionadas e, principalmente, verificar se através destas atividades as crianças estão adquirindo as habilidades informacionais que as tornarão competentes em informação no futuro.

Para finalizar, salienta-se a importância que deve ser dada ao desenvolvimento das habilidades informacionais nas bibliotecas das escolas, começando a desenvolvê-las nas crianças desde cedo, como propõe Kuhlthau (2006). A biblioteca passa a servir como um laboratório de aprendizagem. Ali as crianças vão ganhando novas habilidades gradativamente e chegando logo à competência informacional. A competência informacional passa, então, a se refletir em variados aspectos, como pode ter acontecido com os alunos do Colégio Israelita quando obtiveram melhores notas no ENEM em 2009.

\section{REFERÊNCIAS}

BARBOUR, Rosaline. Grupos focais. Porto Alegre: Artmed, 2010.216 p.

BONOTTO, Martha Eddy Krummenauer Kling. Reflexões sobre a biblioteca escolar. In: SIQUEIRA, Neiva Alves; XAVIER, Adriana Gonçalves; MEDEIROS, Simone Cristina da S. Saberes Específicos. Porto Alegre : Prefeitura Municipal, Secretaria Municipal da Educação, 2007. p. 161-176.

BRASIL. Ministério da Educação. Parâmetros Curriculares Nacionais : introdução aos Parâmetros Curriculares Nacionais. Brasília, DF : MEC/SEF, 1997. Disponível em: <http://portal.mec.gov.br/seb/arquivos/pdf/livro01.pdf>. Acesso em: 17 out. 2011.

CAMPELLO, Bernadete Santos. A escolarização da competência informacional. Revista Brasileira de Biblioteconomia e Documentação : Nova Série, São Paulo, v. 2, n. 2, p. 63-77, dez. 2006. Disponível em:

<http://www.febab.org.br/rbbd/ojs2.1.1/index.php/rbbd/article/view/18/6>. Acesso em: 6 set. 2011. 
Letramento informacional : função educativa do bibliotecário escolar. Belo Horizonte : Autêntica Editora, 2009. 79 p.

CARPALLO BAUTISTA, Antonio. La formación de usuarios en las bibliotecas escolares. In: La nueva alfabetización : un reto para la educación del siglo XXI. [2006], p. 1-11. Disponível em: <http://www.cesdonbosco.com/revista/congreso/03Antonio\%20Carpallo\%20Bautista.pdf>. Acesso em: 15 maio 2012.

CARVALHO, Maria da Conceição. Educação de usuário em bibliotecas escolares : considerações gerais. Revista de Biblioteconomia de Brasília, v. 9, n.1, p. 22-29, jan./jun. 1981. Disponível em:

<http://www.brapci.ufpr.br/download.php?dd0=16932>. Acesso em: 12 out. 2011.

CAVALCANTE, Lídia Eugênia. Políticas de formação para a competência informacional : o papel das universidades. Revista Brasileira de Biblioteconomia e Documentação, São Paulo, v. 2, n. 2, p. 47-62, dez. 2006. Disponível em: <http://www.febab.org.br/rbbd/ojs-2.1.1/index.php/rbbd/article/view/17/5>. Acesso em: 11 out. 2011.

COELHO, Nelly Novaes. Literatura Infantil : teoria, análise, temática. São Paulo : Moderna, 2000. 284 p.

COLÉGIO ISRAELITA BRASILEIRO. [Portal do colégio]. Porto Alegre, 2012. Disponível em: <http://www.colegioisraelita.com.br/>. Acesso em: 22 nov. 2011.

DELACOURS-LINS, Sylvie. Olha! Vem cá ver! : Leituras compartilhadas das crianças na mediateca. In: CONGRESSO INTERNACIONAL EM ESTUDOS DA CRIANÇA - INFÂNCIAS POSSÍVEIS, MUNDOS REAIS, 1, 2008, Braga. ABZ da leitura : orientações teóricas. Disponível em:

<http://195.23.38.178/casadaleitura/portalbeta/bo/documentos/ot_sylvie_delcours_a. pdf>. Acesso em: 19 abr. 2012.

DUDZIAK, Elisabeth Adriana. Information Literacy : princípios, filosofia e práticas. Ciência da Informação, Brasília, v. 32, n. 1, p. 23-35, jan./abr. 2003. Disponível em: <http://www.scielo.br/pdf/ci/v32n1/15970.pdf>. Acesso em: 12 out. 2011.

GIL, Antonio Carlos. Métodos e técnicas de pesquisa social. 6. ed. São Paulo : Atlas, 2010. $200 \mathrm{p}$.

IFLA; UNESCO. Manifesto IFLA/UNESCO para biblioteca escolar. São Paulo, 2002. 4 p.

KIESER, Herta; FACHIN, Gleisy Regina Bóries. Biblioteca escolar : espaço de interação entre bibliotecário-professor-aluno-informação - um relato. In:

CONGRESSO BRASILEIRO DE BIBLIOTECONOMIA E DOCUMENTAÇÃO, 19., 2000, Porto Alegre. Diálogos científicos. Disponível em: <http://dici.ibict.br/archive/00000743/01/T083.pdf>. Acesso em: 8 out. 2011. 
KUHLTHAU, Carol Collier. Como usar biblioteca na escola : um programa de atividades para o ensino fundamental. 2. ed. Belo Horizonte : Autêntica, 2006. 303 p.

MONFASANI, Rosa Emma; CURZEL, Marcela Fabiana. Usuarios de la información : formación y desafíos. Buenos Aires : Alfagrama, 2006. 222 p.

OLIVEIRA, Sueli Ferreira Júlio de. A contribuição dos esforços de educação de usuário para a formação dos usuários de informação tecnológica. In: CONGRESSO BRASILEIRO DE BIBLIOTECONOMIA E DOCUMENTAÇÃO, 19., 2000, Porto Alegre. Diálogos científicos. Disponível em:

<http://dici.ibict.br/archive/00000818/01/T166.pdf>. Acesso em: 29 mar. 2012.

PACHECO, Rosane da Silva. Informática educacional e educação infantil : uma relação possível? 2006. 144 f. Dissertação (Mestrado em Educação)-Universidade Católica de Petrópolis, Petrópolis, 2006. Disponível em:

<http://www.ucp.br/html/joomlaBR/images/dissertacoes_novas/2006/Rosane\%20da \%20Silva\%20Pacheco.pdf>. Acesso em: 10 abr. 2012.

SANTOS, Gláucia Maria da Costa; BARROS, Daniela Melaré Vieira. Escola de tempo integral : a informática como princípio educativo. Revista Iberoamericana de Educación, [Madrid], v. 46, n. 8, p. 1-11, 15 ago. 2008. Disponível em: <http://www.rieoei.org/deloslectores/2400Vieira.pdf>. Acesso em: 25 abr. 2012.

SANTOS, Marlene Sousa. Multimeios na biblioteca escolar. In: GARCIA, Edson Gabriel. Biblioteca escolar : estrutura e funcionamento. São Paulo : Loyola, 1989. p. 97-108.

SOUZA, Maria Anunciação. A contação de história como resposta de intervenção pedagógica. Webartigos. [S.I.], 2009. Disponível em: <http://www.webartigos.com/artigos/a-contacao-de-historia-como-resposta-deintervencao-pedagogica/22105/>. Acesso em: 24 abr. 2012.

TARGINO, Maria da Graça. A biblioteca na concepção de escolares : influência de variáveis do ambiente escolar. 1983. 187 f. Dissertação (Mestrado em Biblioteconomia)-Universidade Federal da Paraíba, João Pessoa, 1983.

VYGOTSKY, Lev Semynovich. Pensamento e linguagem. 2. ed. São Paulo : Martins Fontes, 1998. 135 p.

\section{Title}

Development of informational skills: a study of the user education activities applied in Israelita College's library

\section{Abstract}


Introduction: To achieve information literacy it is necessary learn skills for search and use of information, which should begin to be developed early by the activities of user education applied in school libraries. Evaluate the actions of user education is valid to find if the children internalize the knowledge they are receiving.

Objective: Evaluate the ratio of the skills developed by children from 1styear of Israelita College Elementary School of Porto Alegre / RS, with the skills proposed by Kuhlthau for Phase I, Step 1, corresponding to the age of four to six years.

Methodology: Data were collected through observation and focus group. They were analyzed qualitatively.

Results: The results indicate that children have most of the skills proposed by the author and those which are not fully developed can be improved by restructuring activities implemented and, other skills, in the end of the year, when completing the literacy.

Conclusions: The study considers the evaluations essential because with them it is possible estimate if students have acquired the skills practiced in the actions of user education.

Keywords: Development of informational skills. User education. School library. Assessment skills informational.

\section{Título}

Desarrollo de habilidades informacionales: un estudio de las actividades de formación de usuarios implementado en la biblioteca del Colegio Israelita

\section{Resumen}

Introducción: Para lograr la alfabetización informacional es necesario aprender una serie de habilidades de búsqueda y uso de la información que deben empezar a desarrollarse desde la edad temprana a través de los programas de formación de usuarios empleados en las bibliotecas escolares.

Objetivo: Este estudio investiga la relación de las habilidades desarrolladas por los niños de primer año de la escuela primaria del Colegio Israelita de Porto Alegre/RS, con las destrezas propuestas por la autora Kuhlthau para la Fase I, etapa 1, que corresponde a la edad de cuatro a seis años.

Metodología: Los datos fueron recogidos mediante la observación y grupo de enfoque y fueron analizados cualitativamente.

Resultados: Los resultados demostraron que los niños tienen la mayor parte de las destrezas propuestas por la autora y los que no están completamente desarrollados pueden evolucionar a través de las actividades propuestas por este estudio. Las demás destrezas se desarrollan al final del año, después de completar la alfabetización.

Conclusiones: El estudio encuentra que las evaluaciones son primordiales, porque a través de ellas se obtienen los resultados que comprueban si los estudiantes han logrado alcanzar las destrezas practicadas en los programas de formación de usuarios.

Palabras clave: Desarrollo de habilidades informacionales. Formación de usuarios. Biblioteca escolar. Evaluación de habilidades informacionales.

Recebido em: 22.04.2013

Aceito em: 17.06.2015 